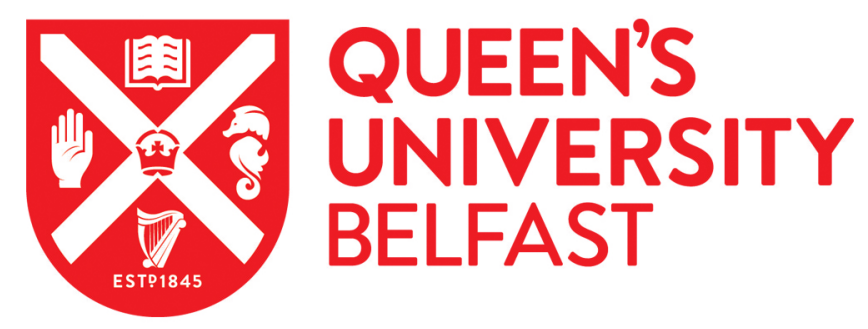

\title{
Design Rules for Stiffened Panel Buckling Containment Features
}

Houston, G., Quinn, D., Murphy, A., \& Bron, F. (2017). Design Rules for Stiffened Panel Buckling Containment Features. Thin-Walled Structures, 116, 69-81. https://doi.org/10.1016/j.tws.2017.03.006

Published in:

Thin-Walled Structures

Document Version:

Peer reviewed version

Queen's University Belfast - Research Portal:

Link to publication record in Queen's University Belfast Research Portal

Publisher rights

(C) 2017 Elsevier.

This manuscript version is made available under the CC-BY-NC-ND 4.0 license http://creativecommons.org/licenses/by-nc-nd/4.0/,which permits distribution and reproduction for non-commercial purposes, provided the author and source are cited.

\section{General rights}

Copyright for the publications made accessible via the Queen's University Belfast Research Portal is retained by the author(s) and / or other copyright owners and it is a condition of accessing these publications that users recognise and abide by the legal requirements associated with these rights.

Take down policy

The Research Portal is Queen's institutional repository that provides access to Queen's research output. Every effort has been made to ensure that content in the Research Portal does not infringe any person's rights, or applicable UK laws. If you discover content in the Research Portal that you believe breaches copyright or violates any law, please contact openaccess@qub.ac.uk. 


\title{
Design Rules for Stiffened Panel Buckling Containment Features
}

\author{
G. HOUSTON, D. QUINN and A. MURPHY \\ Queen's University Belfast, Belfast, N. Ireland, BT9 5AH \\ F. BRON \\ Constellium Technology Center, CS10027, 38341 Voreppe Cedex France
}

\begin{abstract}
This paper presents a method to generate design charts and preliminary design rules for the buckling behaviour of stiffened panel plate elements with buckling containment features. Two modelling approaches are used one with an analytical basis using classical plate theory and one with a numerical basis using the FEM to generate the design charts. The individual modelling approaches are used for cross verification. A novel design chart, based on key geometric ratios is introduced and its use demonstrated. Finally design chart data is explored to demonstrate the formulation of simple design rules which are appropriate for preliminary structural design.
\end{abstract}

\section{Keywords}

Stiffened panel design, buckling containment features, Sub-stiffening, Design charts, Finite Element analysis, buckling equations.

\section{Notation}

$\mathrm{a}, \mathrm{b} \quad$ Plate length in $\mathrm{x}$ - and $\mathrm{y}$-directions, respectively 
Plate thickness

(m)

Number of half-waves into which plate buckles in $\mathrm{x}$ and $\mathrm{y}$ -

$\mathrm{m}, \mathrm{n}$ directions, respectively

$\mathrm{N}_{\mathrm{x}} \quad$ Loading intensity acting in the $\mathrm{x}$-direction

$(\mathrm{N} / \mathrm{m}) / \mathrm{m}$

E Modulus of elasticity of plate material

$\left(\mathrm{N} / \mathrm{m}^{2}\right)$

$v \quad$ Poisson's ratio for plate material

D Plate flexural rigidity, given by $D=\frac{E t^{3}}{12\left(1-v^{2}\right)}$

$(\mathrm{Nm})$

Buckling Coefficient (a non-dimensional coefficient that depends

$\mathrm{k}$ upon conditions of edge restraint)

$\mathrm{A}_{\mathrm{BCF}} \quad$ Individual Buckling Containment Feature area

$\left(\mathrm{m}^{2}\right)$

Effective flexural stiffness of individual Buckling Containment

EI

Features

$\left(\mathrm{Nm}^{2}\right)$

d Pitch of Buckling Containment Features attached to plate

$N_{S} \quad$ Number of Buckling Containment Features attached to plate

Modal coefficient used to modify the effective moment of inertia of

Z

plate and Buckling Containment Feature combination

Distance normal to plane of plate between plate middle surface and

$\bar{Z}$

centre of gravity of Buckling Containment Feature cross section

Resultant bending couples at plate and Buckling Containment

$T_{\theta}$

Feature sub-component junctions

$(\mathrm{Nm} / \mathrm{m})$

Angles of rotation at plate and Buckling Containment Feature sub-

$\theta$ component junctions

Individual stiffnesses of the adjoining plate and Buckling

$\mathrm{A}, \mathrm{B}, \mathrm{C}, \ldots$

Containment Feature sub-components with their various loaded

$(\mathrm{Nm} / \mathrm{m})$ 
edges and remote edge boundary conditions

\begin{tabular}{ccc}
$h_{B C F}$ & \multicolumn{1}{c}{ Individual Buckling Containment Feature height } & $(\mathrm{m})$ \\
$t_{B C F}$ & Individual Buckling Containment Feature thickness & $(\mathrm{m})$ \\
$t_{\text {smeared }}$ & Smeared Plate and Buckling Containment Feature thickness & $(\mathrm{m})$ \\
$\sigma_{\text {critical-buckling }}$ & Overall critical buckling stress & $\left(\mathrm{N} / \mathrm{m}^{2}\right)$ \\
& Buckling stress for local Buckling Containment Feature & $\left(\mathrm{N} / \mathrm{m}^{2}\right)$ \\
$\sigma_{\text {BCF-buckling }}$ & buckling & \\
& Buckling stress for buckling of plate sections between Buckling & $\left(\mathrm{N} / \mathrm{m}^{2}\right)$ \\
$\sigma_{\text {plate-section- }}$ & Containment Features & \\
$\sigma_{\text {combined-buckling }}$ & Buckling Containment Features & $\left(\mathrm{N} / \mathrm{m}^{2}\right)$
\end{tabular}

\subsection{Introduction}

Stiffened panels dominate in the design of aircraft wing, fuselage and empennage structure given their ability to produce light-weight and damage tolerant structures. Panel designs are typically thin-walled, comprising an external skin, stiffened by regularly pitched internal lateral and longitudinal stiffeners. Local buckling of the skin between the stiffeners can be designed to occur below the ultimate collapse load of the panel in cases where this can lighten the design and will not degrade the aerodynamic function of the skin. Small amplitude perturbations in geometry, such as those attributed to skin panel buckling behaviour, can impact the fluid flow around a profile [32-33]. In cases where local skin buckling will degrade the aerodynamic performance, the skin is designed to resist buckling at loads below the ultimate panel collapse load. Similarly in both cases the available design variables, stiffener pitch and skin thickness, are optimised to find the minimum mass 
combination that will result in the local skin buckling performance exceeding that required by the design philosophy [1-6], notwithstanding additional design and manufacturing constraints. Hence the buckling performance of either a non-buckling or post-buckling panel design may be sensitive to skin buckling, and thus methods to increase buckling resistance will have real potential for panel weight savings.

An approach which aims to improve the buckling resistance of panel skins is Buckling Containment Features (BCF) [7], Figure 1. These local skin bay design features have been proposed and experimentally demonstrated to improve the stability and reduce the mass of metallic stiffened panels. The previous studies have revealed that the volumetric reduction in panel skin thickness through the addition of the BCF features can more than offset the BCF mass thus enabling equivalent structural performance with lower panel mass. The introduction of BCF typically has two major effects:

- BCF increase the out-of-plane bending stiffness of the skin bay, increasing the local initial buckling resistance, and resulting in an increased stress magnitude required to cause buckling. The plate and the Buckling Containment Features buckle globally as a unit, supported elastically on the plate edges by the sturdier lateral and longitudinal stiffeners [8].

- BCF also increase the number of available design variables, thus enabling greater opportunity for structural optimisation, considering not only local buckling but also the already noted additional panel design and manufacturing constraints [9]. 
The available published experimental and computational analysis suggests potential mass savings of the order of $15 \%$ when used on thin gauge fuselage panels [8], and mass savings of the order of $4 \%$ to $13 \%$ when used with thick gauge wing panels [10]. However, there is currently no simple direct method available to efficiently determine optimum BCF geometry. There exist only modifications to the current aerospace panel strength analysis procedures that will assess the strength of a BCF panel design [9]. Given the increased number of design variables when using $\mathrm{BCF}$, an iterative design approach is not appropriate and direct design rules which maximise performance are required to enable BCF to become a standard design option. Thus this paper aims to address this weakness by developing direct BCF design charts and from exploration of this data formulate BCF design rules.

The next section outlines the analysis methods to be used. This is followed with cross verification of the analysis methods before exploration of the generated $\mathrm{BCF}$ design data, experimental verification, and the formation of design rules. The final section concludes the paper with a summary of the key findings.

\subsection{Analysis methods}

In order to generate appropriate $\mathrm{BCF}$ design charts a classical plate derivation or a numerical method may be used. For a classical analysis a range of sources [11-13] provide extensions of Classical Plate Theory (CPT) to allow consideration of plate buckling with prismatic and equally spaced stiffeners. Thus by idealising individually the skin bays of a panel assuming simplified edge boundary conditions buckling behaviour may be predicted. The derivation of the classical analysis however includes a number of additional simplifying assumptions 
which impact the potential accuracy of predictions. To overcome the constraints of the classical analysis approach a numerical method may be used. The major weakness of using a numerical method will be that the analysis cost/time will be greater than that required for a classical analysis. The challenge associated with the numerical approach is the selection of appropriate idealisation, loads and boundary conditions and solution procedure. Given the unique potential of both approaches each is developed, cross-verified and used to understand BCF design space, buckling behaviour and prediction accuracy.

\subsection{Classical analysis method}

CPT [11] provides a relationship between the geometry of a simply supported flat plate, Figure 2, its compressive buckling load and the expected longitudinal waveform of the plate once buckled, Equation 1. The theory is suitable for thin plates as it is based upon plane stress and pure plate bending theory. Pure bending theory applies to structures which are symmetric about their neutral axis. The arc length of the neutral axis in its deformed shape must be equal to that prior to deformation. The longitudinal plate edges must therefore be free to translate along the lateral axis of the plate in order for the arc length to remain unchanged. It is also assumed that a cross-section that is plane and perpendicular to the neutral axis prior to bending must be plane and perpendicular after bending. For this reason, the edges must remain plane and rotation about them must occur so that the thickness dimension remains perpendicular to the neutral axis.

$$
N_{x}=\frac{\pi^{2} a^{2} D}{m^{2}}\left(\frac{m^{2}}{a^{2}}+\frac{n^{2}}{b^{2}}\right)^{2}=\frac{\pi^{2} D}{b^{2}} k
$$


Timoshenko and Gere [11] and Seide and Stein [14] introduce methods to predict flexural buckling of plates with prismatic longitudinal stiffeners subject to compression loading. This is analogous to the behaviour of a panel plate section reinforced with Buckling Containment Features and buckling between the larger panel lateral and longitudinal stiffeners. Timoshenko [11] provides individual equations for plates with one, two and an infinite number of stiffeners. Seide [14] derived a single relationship, Equation 2, relating the stiffener-to-skin flexural stiffness ratio $\left(\frac{E I}{d D}\right)$, plate and stiffener geometric properties and number of longitudinal and transverse buckle half-waves, and a buckling coefficient. The equation is solved for the lowest buckling coefficient which determines the buckling waveform (m, n).

$$
\begin{gathered}
\frac{E I}{d D}=\frac{\left(\frac{4 \sqrt{k}\left(\frac{a}{d}\right)^{3}}{\pi^{2} m^{3}}\right)}{\frac{\frac{\sin \phi_{1}}{\phi_{1}}}{\cos \left(\pi \frac{n}{N_{S}+1}\right)-\cos \phi_{1}}-\frac{\frac{\sinh \phi_{2}}{\phi_{2}}}{\cos \left(\pi \frac{n}{N_{S}+1}\right)-\cosh \left(\phi_{2}\right)}} \\
+\frac{\beta^{2} k\left(\frac{A}{d t}\right)}{m^{2}}
\end{gathered}
$$

\section{Equation 2}

where $\quad \phi_{1}=\pi \sqrt{\frac{m d}{a}\left(\sqrt{k}-\frac{m d}{a}\right)}$

and

$$
\phi_{2}=\pi \sqrt{\frac{m d}{a}\left(\sqrt{k}+\frac{m d}{a}\right)}
$$

All prior assumptions discussed for the unstiffened plate theory also apply in the stiffened plate derivations. Each stiffener is considered as a long strut with a boundary condition interaction with the plate along the length of the line junction. The bending deflections of the 
stiffener and plate are assumed equal at their intersections. In the case of the plate and stiffener buckling globally as a unit in an overall mode the plate out-of-plane bending would lead to stiffener in-plane bending. Equilibrium of the stiffened plate therefore involves work done by the external forces during bending of both the plate and stiffener. The theory also assumes that no distortion of the stiffener cross section occurs during buckling, and no interactions occur between buckling modes. Li [15] investigated the interaction between plate buckling and stiffener flexural buckling modes on a plate with one and two stiffeners, suggesting that a reduction in the critical buckling stress of up to $15 \%$ arises from mode interactions. Ignoring mode interactions has thus the potential to result in non-conservative buckling predictions [15]. Stiffener torsional stiffness is also assumed negligible in the discussed classical plate derivations. Lundquist et al. [16-17] established that this effect may be small but does influence the buckling behaviour.

As the preceding analysis is an extension of CPT, and therefore pure bending theory, thus far the stiffened plates have been assumed symmetrical about their neutral axis; with stiffener centroids assumed to coincide with the plate mid-plane. This arrangement is not representative of aerospace applications where stiffeners are necessarily attached to a single side of the skin. Timoshenko [11] deduced a method to consider the additional inertia gained by locating the stiffener on a single side of the plate. The method considers the additional inertia by replacing that of the stiffener about its own centre of gravity by the effective moment of inertia about the mid-plane of the skin. Seide [18] however notes that this is not applicable to all possible stiffened plate geometries. This is because the location of the neutral axis will vary depending on the ratio of stiffener area to skin area. For example, configurations where the stiffener to skin ratio increases above one, towards infinity, will tend to buckle about an axis approaching the centroid of the stiffener. In contrast, 
configurations where the stiffener to skin ratio decreases below one, towards zero, will tend to buckle about an axis approaching the skin mid-plane. To give these ratios some context acceptable aerospace panel cross-sectional ratios will range from 0.3 to 1.0 [34-35]. Seide [18] also derived a solution applicable to aerospace applications by representing the stiffener as being on a single side of the skin. This methodology importantly considers that the location of the bending neutral axis will change with variations of stiffener and skin geometry. The approach introduces a coefficient which adjusts the stiffener-to-skin flexural stiffness ratio for the location of the neutral axis. The coefficient is also dependent on the stiffened plate geometrical variables as well as the buckle waveform $(m, n)$. Equation 3 enables the calculation of the coefficient for a plate with a single stiffener buckling into a single transverse half-wave $(Z)$. Equation 4 calculates a modified effective flexural rigidity ratio $\frac{E I_{\text {offset }}}{d D}$ for a plate with a single stiffener buckling into a single transverse half-wave. The modified effective rigidity ratio $\frac{E I_{\text {offset }}}{d D}$ replaces the flexural rigidity ratio $\frac{E I}{d D}$ in Equation 2. The solution again requires an iterative approach to compute the buckling coefficient. Seide [18] also derived solutions for a plate with two, three, or 'a large number of stiffeners'.

$$
\mathrm{Z}=\frac{1}{4} \frac{\left[(3-v)(1+v) \cosh \left(\frac{2 m \pi d}{a}\right)+2(1+v)^{2}\left(\frac{m \pi d}{a}\right)^{2}+5-2 v+v^{2}\right]}{\sinh \left(\frac{2 m \pi d}{a}\right)+\frac{2 m \pi d}{a}} \frac{m \pi d}{a}
$$

\section{Equation 3}

$$
\frac{E I_{\text {offset }}}{d D}=\frac{E I}{d D}+\frac{1}{1+\mathrm{Z} \frac{A_{B C F}}{d t}} E \mathrm{~A}_{B C F} \frac{(\bar{z})^{2}}{d D}
$$

\section{Equation 4}


Thus far the assembled theory does not consider mode interactions nor potential plate buckling between $\mathrm{BCF}$ or local BCF buckling. Considering stiffness and modes of deformation at individual plate-stiffener intersections [19] and balancing sub-component rotations and corresponding edge couples, it is possible to estimate individual sub-component buckling stresses [20-21]. Such a solution process consists of a search for a minimum value of the longitudinal compressive stress associated with zero values of the total stiffness $\left(\mathrm{T}_{\Theta} / \Theta\right)$ at each intersection line, Equation 5. Where the terms on the right hand side of equation 5 (A, $\mathrm{B}, \mathrm{C}$ etc.) are the individual stiffnesses of the adjoining sub-components with their various loaded edges and remote edge boundary conditions. The process is in essence looking to balance positive stiffnesses in one or more components against negative stiffnesses in adjoining components. By examining modes of deformation at component intersections the interaction of local buckling modes is naturally reflected. The approach determines not only the critical buckling stresses but also the critical buckle half wavelengths. The method assumes that the structure is of infinite length and that no translation of the intersections (junction lines) between individual components occurs. Thus it does not consider interaction between local buckling of components of the cross-section and unit buckling of the entire cross-section (plate plus BCF).

$$
T_{\theta} / \theta=\mathrm{A}+\mathrm{B}+\mathrm{C}
$$

Equation 5

This is the final building block to enable a plate theory prediction of realistic panel designs assuming simplified edge boundary conditions. The theory does have a number of limitations as noted above however such analysis approaches may be sufficiently accurate for initial design [20]. Figure 3 outlines the analysis flowchart to combine the individual calculations. 


\subsection{Finite Element method}

To overcome the limitations within the plate theory approach and to consider local crosssection and entire cross-section buckling mode interactions a Finite Element (FE) approach applying eigenvalue buckling analysis may be used. A wide range of numerical methods are available, some which will require a smaller number of elements to accurately represent buckling behaviour, i.e. the finite strip method [22-24]. As a result, a FE approach is not the most efficient method however the additional computational burden is offset by the absence of any limitations on the geometry and boundary conditions that may be modelled. Crucially the definition of a modelling approach must create a simulation capable of accurately detecting all possible linear elastic buckling mode shapes with loading and boundary conditions as assumed by the preceding CPT analysis. Thus a set of model loads and boundary conditions have been formulated to represent plate designs with BCF subjected to a state of constant stress prior to deformation and edge boundary conditions matching the already described plate theory.

Examining preceding literature, Quinn et al. $[8,25]$ applies FE analysis to model a range of specimen designs with BCF. The idealisation replicate test conditions with a fixed displacement applied across the loaded edges resulting in plate end conditions that are neither simply supported nor clamped, Figure $4 a \& b$. Moreover, the constraint on edge node axial displacements prevents rotation through the stiffener height for a buckling mode with an odd number of axial half-waves. To part overcome this common modelling problem Fenner et al [26] introduces a 'Double Half-bay Model' in which the stiffened plate length is divided equally across a central model boundary condition which constrains panel skin out-of-plane deflections, Figure 4c. As CPT assumes a continuous sinusoidal buckling deformation it is 
therefore valid to assume that in the case of an odd number of longitudinal half-waves zero rotation of the stiffener height occurs at the edge of a 'Double Half-bay Model'. Thus odd number modes can be correctly identified when applying loading via fixed displacement at the model ends. By doubling the total length of the model Fenner et al [26] demonstrates that it is possible to represent both odd and even mode numbers through a single set of MPC relationships, between the model axial edges, Figure 4d [26]. Finally by extending the preceding approach and applying the loading via nodal forces this modelling technique is capable of identifying all buckling deformation shapes for plate designs with BCF. These compression forces allow rotation of the stiffener and provide an equal stress distribution across the whole model. The magnitude of each compressive nodal force is calculated to ensure that the total induced moment about the neutral axis of bending is zero. Figure 5 illustrates the final model loading and boundary conditions, further details on the modelling approach is available in reference [27] including model loading and boundary conditions for shear and combined shear and compression loading.

A linear eigenvalue solution procedure provides a suitable approach to predict initial buckling behaviour (load and modal deformation) for complex structures while minimising computational cost. Such an approach is not capable of representing directly the effects of non-linearity associated with yielding or post-buckling behaviour. However Quinn et al. [9] demonstrated the use of linear eigenvalue analysis output in combination with industrial analysis methods to predict panel buckling and post-buckling behaviour including the effect of material non-linearity. 


\subsection{Verification of analysis methods}

In order to verify the prediction accuracy of the classical analysis and FE methods, both methods were used to create a series of buckling coefficient versus aspect ratio curves for a range of plate designs with varying plate and $\mathrm{BCF}$ geometry. The total range of designs studied considered plates with aspect ratios $(\mathrm{a} / \mathrm{b})$ ranging from 0.5 to 6.0 , with classical analysis results in 0.1 increments and FE simulation results in increments of 0.5 . The study examined from one to four prismatic BCF with the load carrying capacity of the designs increasing throughout the study with incremental increases in BCF height $(0.07$ to $0.25 \mathrm{~mm}$ in $0.005 \mathrm{~mm}$ increments) and skin and BCF thickness ( 1 to $4 \mathrm{~mm}$ in $0.085 \mathrm{~mm}$ increments), all based on a plate pitch of $100 \mathrm{~mm}$. In all the presented results the skin and BCF thicknesses are assumed equivalent (fatigue and damage tolerance requirements may limit and control the practical variation in skin and BCF thickness). The selected design increments resulted in an even distribution of buckling coefficients over the examined aspect ratio range. This allowed in-depth comparison of the two analysis methods over the full range of buckling stress levels and buckling behaviour that can be induced through the use of BCF. The examined panel design space, in terms of geometry and load carrying capacity, covers the typical range of wing and fuselage panel applications.

$$
t_{\text {smeared }}=\frac{t b+N_{S} t_{B C F}\left(h_{B C F}-t\right)}{b}
$$

\section{Equation 6}

Figure 6 presents a sample of the analysis results with the predicted buckling performance converted into a buckling coefficient based on the individual design smeared thickness ( $\left.\mathrm{t}_{\text {smeared }}\right)$, Equation 6. Comparisons are presented for 1 and 2 blade configurations and an 
aspect ratio of 3 and 6 . Examining the results there appears excellent agreement between the two prediction methods for the designs with low buckling coefficients, featuring low to medium height BCF. In these cases the buckling behaviour involves a single lateral halfwave buckle across the structure and one to four longitudinal half-wave buckles along the structure. In all cases the plate sections between the BCF and the BCF themselves follow the buckling waves of the global structure. With higher buckling coefficients and higher ratios of $\mathrm{BCF}$ height to plate width there is divergence between the methods. Ultimately for all designs there is a constant difference observed between the two prediction methods, across the entire aspect ratio range studied. In all cases in which a difference is observed between the two prediction methods, the buckling behaviour involves initial instability of the plate sections between the BCF or buckling of the individual $\mathrm{BCF}$ is predicted. In the FE results these modes also included varying levels of cross-sectional out-of-plane deflection indicating some level of mode interaction. Hence, both methods are suitable for buckling modes in which the plate and BCF buckle as a unit. However the classical analysis method over predicts performance when local instability of plate regions between the BCF or buckling of the $\mathrm{BCF}$ is expected as it fails to capture mode interactions. In order to verify that the FE method was capable of accurately predicting buckling of the plate sections between the $\mathrm{BCF}$ and buckling of the BCF the mesh convergence procedures outlined in Murphy et al. [28] were used to select the minimum mesh density required to represent these buckling modes. The buckling behaviour of rectangular plates with geometries and boundary conditions designed to replicate those of the specimen's individual plate units were carried out. Each analysis set was developed such that a verifying theoretical buckling calculation could be performed [29]. 
Considering the foregoing discussions as well as the assumptions and associated prediction weaknesses of the classical analysis approach, in the following sections design chart data will initially be presented using the FE approach.

\subsection{BCF design data}

Conventional plate buckling coefficients are specific to a set of edge boundary conditions and plate aspect ratio (length divided by width). Thus any plate with matching boundary conditions and aspect ratio may have its buckling stress calculated using the coefficient and the specific thickness and material properties of the plate [11-13]. A similar approach is highly desirable for plate designs with BCF. As a result coefficients which can be used to calculate the buckling performance of the plate with a particular set of edge boundary conditions and geometry ratios, including the BCF geometry, is required. The coefficient should be independent of material properties and should capture the plate and BCF geometry in a ratio to the plate width. However, given the more complex geometry of a plate including $\mathrm{BCF}$ the cross-sectional area per unit width is not solely dependent on the plate thickness. Thus two coefficients are required for design, a stress based buckling coefficient and a load based buckling coefficient. Achieving this, a single dataset may be created for each BCF configuration (i.e. number and distribution of $\mathrm{BCF}$ ), plate aspect ratio and edge boundary conditions. From a dataset a coefficient should be easily extractable using a set of geometric ratios and the coefficient should then allow the calculation of the buckling stress or load considering the specific thickness and material properties of the design. Table 1 presents a set of geometric ratios which allow the creation of the required independent coefficients. Considering typical panel structure found in civil transport aircraft wing and fuselage design, and typical load intensities (force applied per unit width) on such structures, a suitable range 
for the geometric ratios incorporating the majority of aircraft panel applications can also be determined, Table 1.

Figure 7 illustrates an exemplar dataset created for a single BCF configuration (i.e. a single blade cross-section BCF centrally located on a plate with simply supported unloaded edges and periodic boundary conditions on its loaded edges, as described in Section 2.2). The figure presents four design charts, with each chart representing a single plate aspect ratio. The dataset is presented as $2 \mathrm{D}$ contour line plots in which the horizontal and vertical axes represent the ratio of $\mathrm{BCF}$ height to plate width and skin thickness to plate width respectively. The plotted coefficient curves represent combinations of geometry ratios which result in a constant coefficient value (stress and load). For a combination of skin thickness to plate width ratio and $\mathrm{BCF}$ height to plate width ratio a pair of coefficients may be determined. Using Equation 7 or 8 and the extracted coefficients, along with the specific design plate width and material properties the buckling performance of the design may be calculated. The filled background of the chart represents varying magnitudes of design smeared plate thickness (divided by the plate width) which enables the smeared thickness to be calculated using Equation 6, for specific combinations of geometric ratios and plate width. Finally the number of plate longitudinal buckling waves is also identified in the figure. If the number of longitudinal waves (m-waves) is identified then the structure experiences a single transverse half-wave. In design regions where buckling occurs between the $\mathrm{BCF}$, or buckling of the BCF occurs, the chart identifies the buckling waveform as $n>1$. This allows understanding of the buckling behaviour and better interpretation of the data. 
Figure 8 illustrates an example calculation using a design chart. Table 2 provides the basic design target for load and stress, along with the material properties and geometry constraints. The design chart to be used is for a plate with a single centrally located BCF of aspect ratio 4.0 and simply supported on its unloaded edges and periodic boundary conditions on its loaded edges. The desired design is the minimum mass design which prevents plate yielding or buckling below the target load. To illustrate the identification of an optimum design, invalid regions of the design space are individually filled white, Figure 8, with the valid design regions retaining the original colour scale.

- Buckling stress constraint - First the target buckling stress is used to identify the required stress coefficient, defining the upper bound of the design space - buckling performance beyond this boundary (i.e. a higher buckling coefficient) would be of no benefit and would induce a mass penalty. It is worth noting here that the use of BCF enables the buckling stress to be increase beyond that which would be reasonable with a conventional plate design, hence it is feasible to target buckling to occur at the material yield stress. Equation 7 allows calculation of the stress coefficient, which is equal to $7.0 \times 10^{-3}$ for this example, Figure 8.

- Buckling load constraint - The load based buckling coefficient imposes a minimum bound on the design space as buckling of the plate should not occur below this level. Equation 8 allows the calculation of the minimum load based buckling coefficient, and for this example the minimum coefficient is equal to $17.5 \times 10^{-3}$, Figure 8 .

- Gross yielding constraint - The solution procedure must also consider material yield stress. The required minimum smeared thickness to withstand the design load intensity while not exceeding the material yield stress may be calculated using Equation 9. For this example, the minimum smeared thickness is $1.25 \mathrm{~mm}$. Thus the yielding constraint 
eliminates only configurations within the design space which have been previously eliminated, Figure 8.

- $\quad \mathbf{h}_{\text {BCF }}$ height constraint - Considering the given maximum BCF height $(18 \mathrm{~mm})$, and the specified plate width $(100 \mathrm{~mm})$, Table 2 , an additional design space boundary is required at $\mathrm{h}_{\mathrm{BCF}} / \mathrm{b}=0.18$, Figure 8 .

Based on the determined design space the ' $\mathrm{X}$ ' in Figure 8 indicates geometry of smeared thickness equal to $2.60 \mathrm{~mm}$ as the minimum mass configuration. Table 3 provides full details of the optimal design. It is also possible to calculate the optimum geometry for configurations involving a larger number of BCF using the above-described methodology. Table 3 provides details of the optimum design calculated considering for equivalent configurations but with 2 , 3 and 4 BCF.

$$
\begin{gathered}
\sigma_{\text {buckling }}=C_{1}\left(\frac{E}{\left(1-v^{2}\right)}\right) \\
P_{\text {buckling }}=C_{2} \cdot \mathrm{b}\left(\frac{E}{\left(1-v^{2}\right)}\right)
\end{gathered}
$$

Equation 7

Equation 8

$$
\text { Minimum Smeared Thickness }=\frac{\text { Maximum Load Intensity }}{\sigma_{\text {yield }}} \quad \text { Equation } 9
$$

Examining the exemplar dataset shown in Figure 7 and first focusing on the stress buckling coefficients $\left(C_{1}\right)$ it is possible to interpret the buckling behaviour within the studied design space. First it is worthy of note that there is significant coefficient variation in each chart, ranging from $1 \times 10^{-3}$ in the bottom left to a maximum of $15 \times 10^{-3}$ in the top right. The lower 
end of each chart represents configurations with low plate and BCF thickness, the upper end represents configurations of high thickness. The left side of each chart represents configurations with low BCF height, and the right side represents configurations of high $\mathrm{BCF}$ height. Thus in the zones with low buckling coefficients (bottom left) there is configurations of low thickness and low BCF height, and in the zones with high buckling coefficients (top right) there are configurations of combined high thickness and BCF height. In addition, the smeared thickness, which represents unit weight, also varies from low to high, from the bottom to the top and from the left to the right of each chart. Accordingly lines of constant weight run with a slight decline from left to right.

In the top left region of each chart, the combination of short BCF and high thicknesses implies that the ratio of $\mathrm{BCF}$ to plate flexural rigidity will be small and plate buckling behaviour will be dominant, with the plate and BCF buckling as a unit into multiple longitudinal half-waves. Individually decreasing thickness or increasing BCF height will increase the ratio of $\mathrm{BCF}$ to plate flexural rigidity, this increases the influence of the $\mathrm{BCF}$ over the buckling behaviour and reduces the number of longitudinal half-wave buckles, as less plate and more column behaviour is seen to occur. Simultaneously decreasing thickness and increasing BCF height will ultimately move the design into the bottom right of the charts, and here the low thickness and high width of the individual units makes it possible for local buckling, either plate buckling between BCF or buckling of BCF to occur.

Examining a single curve of constant buckling coefficients $\left(C_{1}\right)$ the same pattern can be seen in each chart. Starting in the top left where the designs have high plate and BCF thickness but small BCF height. Increasing BCF height allows reduction of the plate and BCF thicknesses 
whiles maintaining the constant stress coefficient value. The increase in cross-sectional area due to the increased BCF height is smaller than the decrease in cross-sectional area caused by the thickness reductions and thus unit weight is decreased. The rate of decrease is dependent on buckling mode and the proximity to a change in mode, with reductions in the value of $\mathrm{m}$ (longitudinal buckle half-waves) resulting in reductions in the average slope of the constant buckling coefficient curves. Ultimately when the buckling form changes to $\mathrm{n}>1$, that is to say buckling between the BCF or buckling of the BCF occurs, the slope of the constant buckling coefficient curves become positive. At this point increasing BCF height to maintain the constant buckling coefficient value requires increased plate and $\mathrm{BCF}$ thickness, thus increasing cross-sectional area and unit weight. Ultimately the minimum smeared thickness or unit weight for a given buckling coefficient is at the transition from global buckling of the plate and $\mathrm{BCF}$ as a unit to local buckling of the skin between the BCF or buckling of the BCF.

Considering the influence of aspect ratio, at greater aspect ratios more longitudinal buckle half-waves are observed. As aspect ratio is reduced the maximum and minimum number of longitudinal buckles in each chart decreases. The reduction in the number of observed longitudinal buckle half-waves is due to the plate component of the buckling behaviour, were the minimum energy state is found with square half-waves, and thus aspect ratio dictates waveform. Also observable from Figure 7 is the boundary between global and local buckling behaviour, as aspect ratio changes the boundary shifts in terms of $t / b$ and $h_{B C F} / b$ both in location and in slope. Given only the small number of aspect ratios presented the buckling mode boundary shifts do not appear to follow a simple pattern. The reason for this is that only a discrete number of buckle half-waves may form, either global or local, and thus aspect ratio interacts with both $\mathrm{t} / \mathrm{b}$ and $\mathrm{h}_{\mathrm{BCF}} / \mathrm{b}$, determining unique boundary locations for each 
aspect ratio. Figure 9 illustrates the variation of stress buckling coefficient with aspect ratio for a single $B C F$ design $\left(h_{B C F} / b=0.158, t / b=0.025\right)$. The data is presented in aspect ratio intervals of 0.5 and only the critical buckling modes are plotted. In addition stress buckling coefficients in an equivalent form, Equation 7, are presented for a flat plate and similar trends are seen. As the aspect ratio increases the number of longitudinal half-waves increase and at each buckling mode change there is significant local buckling coefficient change. Figure 9 also illustrates how the introduction of $\mathrm{BCF}$ and the resultant increase in the ratio of $\mathrm{BCF}$ to plate flexural rigidity elongates the buckle waveforms of the structure. For the flat plate the number of longitudinal half-waves is approximately equal to aspect ratio, but for the exemplar BCF design the number of longitudinal half-waves is approximately equal to half the aspect ratio.

Finally, if we now consider the influence of the number of BCF used to stiffen a plate, Figure 10 illustrates an exemplar dataset created for a single aspect ratio (5.0) but considering one, two, three and four identical and equally spaced BCF. Examining the charts it is first important to note that the magnitude and rate of change of smeared thickness, and thus unit weight, changes with increasing BCF numbers. Lines of constant smeared thickness have greater negative slope with increasing BCF numbers, Figure 10, as increasing BCF height is factored by the number of BCF when calculating cross-sectional area. Examining the charts the general buckling behaviour of plates with two or more BCFs is similar to that of a plate with a single BCF. As before, the minimum smeared thickness or unit weight for a given buckling coefficient is at the transition from global to local buckling behaviour. The introduction of more BCFs appears to have the greatest effect within the region of the charts where this transition occurs, the bottom right. Here the size of the local buckling zone is reduced with increasing numbers of $\mathrm{BCF}$, being replaced by global buckling with a single 
longitudinal half-wave. Adding BCF directly reduces the width of the plate sections between each BCF thereby significantly increasing their stability and thus reducing this form of local buckling and hence reducing the amount of local buckling behaviour in the charts. In addition, increasing the number of BCF employed, particularly in the region of the charts with high $\mathrm{BCF}$, will significantly increase the ratio of $\mathrm{BCF}$ to plate flexural rigidity, allowing column buckling behaviour to dominate and designs to buckle with single longitudinal halfwaves.

\subsection{Experimental Verification}

The experimental validation considers two specimens manufactured from high strength aluminium-lithium alloy using standard aerospace machining technology. Figure 11 illustrates the specimen general configurations. The specimens consist of a full central longitudinal bay $(500 \mathrm{~mm})$ and two outer half bays. Representative rib features divide each bay along the length of the panel. Transversely, each specimen consists of three primary stiffeners, each with a pitch of $112.5 \mathrm{~mm}$. Each specimen has four skin bays across the width. Thus the aspect ratio of each skin bay is 4.9. The stiffeners are T-section and there are two blade shaped BCF in each skin bay. In Specimen 1 the height of each BCF is $8.8 \mathrm{~mm}$ and the thickness of each BCF is $2.3 \mathrm{~mm}$, and each $\mathrm{BCF}$ blends into the integral feet at each rib location and the skin thickness is $2.1 \mathrm{~mm}$. Considering specimen 2 the height of each BCF is $10 \mathrm{~mm}$ and the thickness of each BCF is $2.0 \mathrm{~mm}$. In contrast to Specimen 1, each BCF is continuous along the length of the panel but non-prismatic as they pass through mouse holes in each of the rib features. The skin thickness is $2.0 \mathrm{~mm}$ but with localised thickness increases at rib locations. 
Both of the specimens were tested using a load controlled $1500 \mathrm{kN}$ capacity hydraulic testing machine. The rib features were restrained appropriately in order to prevent out-of-plane displacement, but permit the panel to compress under loading. The longitudinal edges of each specimen were also restrained in order to represent the presence of adjacent structure. Table 4 presents the experimental measured initial buckling and ultimate collapse loads along with the out-of-plane buckling waveforms (outputs from a Digital Image Correlation system).

The specimen initial buckling behaviour was predicted using the described FE and theoretical methods, and combined with an industrial sizing procedure [9] to predict the specimen initial buckling and ultimate collapse loads. Referring to the upper right hand side design chart in Figure 10, the buckling modes for both Specimen $1\left(\mathrm{~h}_{\mathrm{BCF}} / \mathrm{b}=0.099, \mathrm{t}_{\mathrm{BCF}} / \mathrm{b}=0.020\right)$ and Specimen $2\left(\mathrm{~h}_{\mathrm{BCF}} / \mathrm{b}=0.110, \mathrm{t}_{\mathrm{BCF}} / \mathrm{b}=0.018\right)$ is accurately predicted as two longitudinal halfwaves per skin bay. Table 4 also presents the percentage difference between each of the prediction methods and the experimental data. The initial buckling predictions show a higher degree of conservatism (a maximum of 19.8\%) than the collapse predictions (a maximum of $6.8 \%$ ). This degree of conservatism is typical within aerospace test programmes using early design prediction techniques [30-31]. The conservatism can be understood by considering the experimental boundary conditions and those represented by the prediction methods. The theoretical framework and the FE methodologies represent simply supported boundary conditions on the skin bay edges. These boundary conditions prevent out-of-plane displacement but provide zero rotational support. In contrast, within the experimental tests the primary stiffeners and rib structure(s) define the boundaries of each skin bay and provide rotational support to the adjacent structure and this will increase the buckling load. 


\subsection{BCF design rules}

Having created a significant volume of design charts a series of regression studies were undertaken to formulate a series of simple design rules for preliminary structural design. From the preceding results and discussions it is clear that the minimum smeared thickness or unit weight for a given stress based buckling coefficient is at the transition from global buckling of the plate and $\mathrm{BCF}$ as a unit, to local buckling of the plate sections between $\mathrm{BCF}$ or local buckling of the BCF. Thus for each generated design chart it is possible to regress an equation in terms of $t / b$ and $h_{\mathrm{BCF}} / \mathrm{b}$ for the transition between the relevant buckling modes which may be used as a simple design rule. Figure 12 presents an example of such a design rule.

\subsection{Conclusions}

Simple and direct design rules which maximise performance are required to enable stiffened panel buckling containment features to become a standard design option. This paper addresses this weakness by developing design charts and from exploration of these formulates a series of simple design rules for preliminary structural design. The generated charts have been verified through the use of two analysis methods, one based on classical plate theory and the other based on finite element eigenvalue simulations. The data was also validated at a number of individual design points against preceding experimental data, across a range of wing and fuselage panel applications. 


\subsection{Acknowledgement}

The authors gratefully acknowledge the technical and financial support of Constellium Technology Center in Voreppe, France.

\subsection{References}

[1] Jeom Kee Paik, Sjoerd van der Veen, Alexandre Duran, Matthew Collette, Ultimate compressive strength design methods of aluminum welded stiffened panel structures for aerospace, marine and land-based applications: A benchmark study, Thin-Walled Structures, Volume 43, Issue 10, October 2005, Pages 1550-1566

[2] Wei Wang, S. Guo, Nan Chang, Wei Yang, Optimum buckling design of composite stiffened panels using ant colony algorithm, Composite Structures, Volume 92, Issue 3, February 2010, Pages 712-719

[3] J.F. Caseiro, R.A.F. Valente, A. Andrade-Campos, J.W. Yoon, Elasto-plastic buckling of integrally stiffened panels (ISP): An optimization approach for the design of crosssection profiles, Thin-Walled Structures, Volume 49, Issue 7, July 2011, Pages 864-873

[4] P.E. Fenner, A. Watson, Finite element buckling analysis of stiffened plates with filleted junctions, Thin-Walled Structures, Volume 59, October 2012, Pages 171-180

[5] R. Wilson, A. Murphy, M.A. Price, C. Glazebrook, A preliminary structural design procedure for laser beam welded airframe stiffened panels, Thin-Walled Structures, Volume 55, June 2012, Pages 37-50

[6] K.L. Tran, C. Douthe, K. Sab, J. Dallot, L. Davaine, A preliminary design formula for the strength of stiffened curved panels by design of experiment method, Thin-Walled Structures, Volume 79, June 2014, Pages 129-137 
[7] A. Murphy, D. Quinn, P. Mawhinney, M. Ozakca, S.van der Veen. Tailoring static strength performance of metallic stiffened panels by selective local sub-stiffening. $47^{\text {th }}$ AIAA/ASME/ASCE/AHS/ASC Structures, Structural Dynamics, and Materials Conference, Newport, Rhode Island, May 2006, AIAA-2006-1944

[8] D. Quinn, A. Murphy, W. McEwan, F. Lemaitre, Stiffened panel stability behaviour and performance gains with plate prismatic sub-stiffening, Thin-Walled Structures, Volume 47, Issue 12, December 2009, Pages 1457-1468

[9] D. Quinn, A. Murphy, C. Glazebrook. Aerospace stiffened panel initial sizing with novel skin sub-stiffening features. International Journal of Structural Stability and Dynamics, October 2012, Vol. 12, No. 05 (doi: 10.1142/S0219455412500605)

[10] G. Houston, D. Quinn, A. Murphy, and F. Bron. Wing Panel Design with Novel SkinBuckling Containment Features. Journal of Aircraft, 2015 http://dx.doi.org/10.2514/1.C033540

[11] S.P. Timoshenko and J.M. Gere. Theory of Elastic Stability. s.1. : McGraw-Hill, 1963. 9780070702417.

[12] P.S. Bulson, The Stability of Flat Plates. s.1. : Chatto \& Windus, 1970. 9780701114787.

[13] H.G. Allen, and P.S. Bulson, Background to Buckling. s.l. : McGraw-Hill, 1980. 9780070841000.

[14] P. Seide, and M. Stein, Compressive Buckling of Simply Supported Plates with Longitudinal Stiffeners. No. 1825, s.l. : National Advisory Committee for Aeronautics, 1949.

[15] L. Li, and P. Bettess, Buckling of stiffened plates and design of stiffeners, International Journal of Pressure Vessels and Piping, Volume 74, Issue 3, December 1997, Pages 177-187 
[16] E.E. Lundquist and E.Z. Stowell, Restraint Provided A Flat Rectangular Plate by a Sturdy Stiffener along an Edge of the Plate. National Advisory Committee for Aeronautic (NACA), SR-190, 1941.

[17] E.E. Lundquist and E.Z. Stowell, Critical Compressive Stress for Flat Rectangular Plates Supported Along Edges and Elastically Restrained Against Rotation along the Unloaded Edges. National Advisory Committee for Aeronautics (NACA), NACA-SR$189,1941$.

[18] P. Seide, The effect of longitudinal stiffeners located on one side of a plate on the compressive buckling stress of the plate-stiffener combination. National Advisory Committee for Aeronautic (NACA), Langley, Technical Note 2873, 1953.

[19] Anon. Stiffness of loaded flat strips under sinusoidally distributed bending couples at their edges (for use in local buckling calculations) (Uniaxial or biaxial loading. Isotropic or orthotropic materials). ESDU, HIS, Engineering Sciences Data Item No. ESDU 73007, July 1973.

[20] Anon. Local buckling of compression panels with unflanged integral stiffeners. ESDU, HIS, Engineering Sciences Data Item No. ESDU 70003, January 1970.

[21] Anon. Estimation of the initial buckling stress under uniaxial compression of a skin with integral unflanged stiffeners. ESDU, HIS, Engineering Sciences Data Item No. ESDU 02.01.34, June 1954.

[22] H.R. Ovesy, J. Loughlan, S.A.M. GhannadPour, G. Morada, Geometric non-linear analysis of box sections under end shortening, using three different versions of the finite-strip method, Thin-Walled Structures, Volume 44, Issue 6, June 2006, Pages 623637 
[23] E. Riks, Buckling and post-buckling analysis of stiffened panels in wing box structures, International Journal of Solids and Structures, Volume 37, Issues 46-47, 20 November 2000, Pages 6795-6824

[24] L. Iuspa, E. Ruocco, Optimum topological design of simply supported composite stiffened panels via genetic algorithms, Computers \& Structures, Volume 86, Issues 17-18, September 2008, Pages 1718-1737

[25] D. Quinn, A. Murphy, W. McEwan, F. Lemaitre, Non-prismatic sub-stiffening for stiffened panel plates-Stability behaviour and performance gains, Thin-Walled Structures, Volume 48, Issue 6, June 2010, Pages 401-413

[26] P. Fenner, A. Watson. Eliminating End Effects for Theoretical Panel Buckling with FEM. In: Proceedings of the 51st AIAA/ASME/ASCE/AHS/ASC Structures, Structural Dynamics, and Materials Conference, AIAA, Orlando 2010.

[27] G. Houston, D. Quinn and A. Murphy. Design methods for stiffened panel buckling containment features under compression and shear loading. The 7th International Conference on Thin-Walled Structures, Busan, Korea, 2014, ICTWS2014-0702 (7-1), pp. 1-9.

[28] A. Murphy, M. Price, A Gibson. Toward virtual testing of airframe stiffened panels. In: Royal Aeronautical Society - Virtual Testing Conference, London; 2006.

[29] Anon. ESDU Structures Sub-Series. Engineering Sciences Data Units. London: ESDU International Ltd; 1965.

[30] C Lynch, A Murphy, M Price, A Gibson. The Computational Post Buckling Analysis Of Fuselage Stiffened Panels Loaded in Compression. Journal of Thin-Walled Structures, Vol 42/10, 2004, pp 1445-1464. 
[31] A Murphy, M Price, C Lynch, A Gibson. The Computational Post Buckling Analysis Of Fuselage Stiffened Panels Loaded In Shear. Thin-Walled Structures, Vol 43/9, 2005, pp 1455-1474.

[32] A Garzon and M W Roberts, Effect of a Small Surface Wave on Boundary-Layer Transition, In: 43rd Fluid Dynamics Conference, Fluid Dynamics and Co-located Conferences, San Diego, 2013.

[33] M Denison, S P. Wilkinson, and P Balakumar, On the Effect of Rigid Swept Surface Waves on Turbulent Drag, In: 45th AIAA Fluid Dynamics Conference, AIAA Aviation, Dallas, 2015.

[34] M.C. Niu. "Airframe Structural Design". 1st Edition, Conmilit Press Ltd, Hong Kong, 1998.

[35] M. Lillico, R. Butler, G. W. Hunt, A. Watson, D. Kennedy. Postbuckling of Stiffened Panels Using Strut, Strip, and Finite Element Methods. AIAA Journal, Vol. 41, 2003, pp 1172-1179. 
Tables:

Table 1 - Lower and upper limits of the non-dimensional terms used to describe stiffened plate geometry

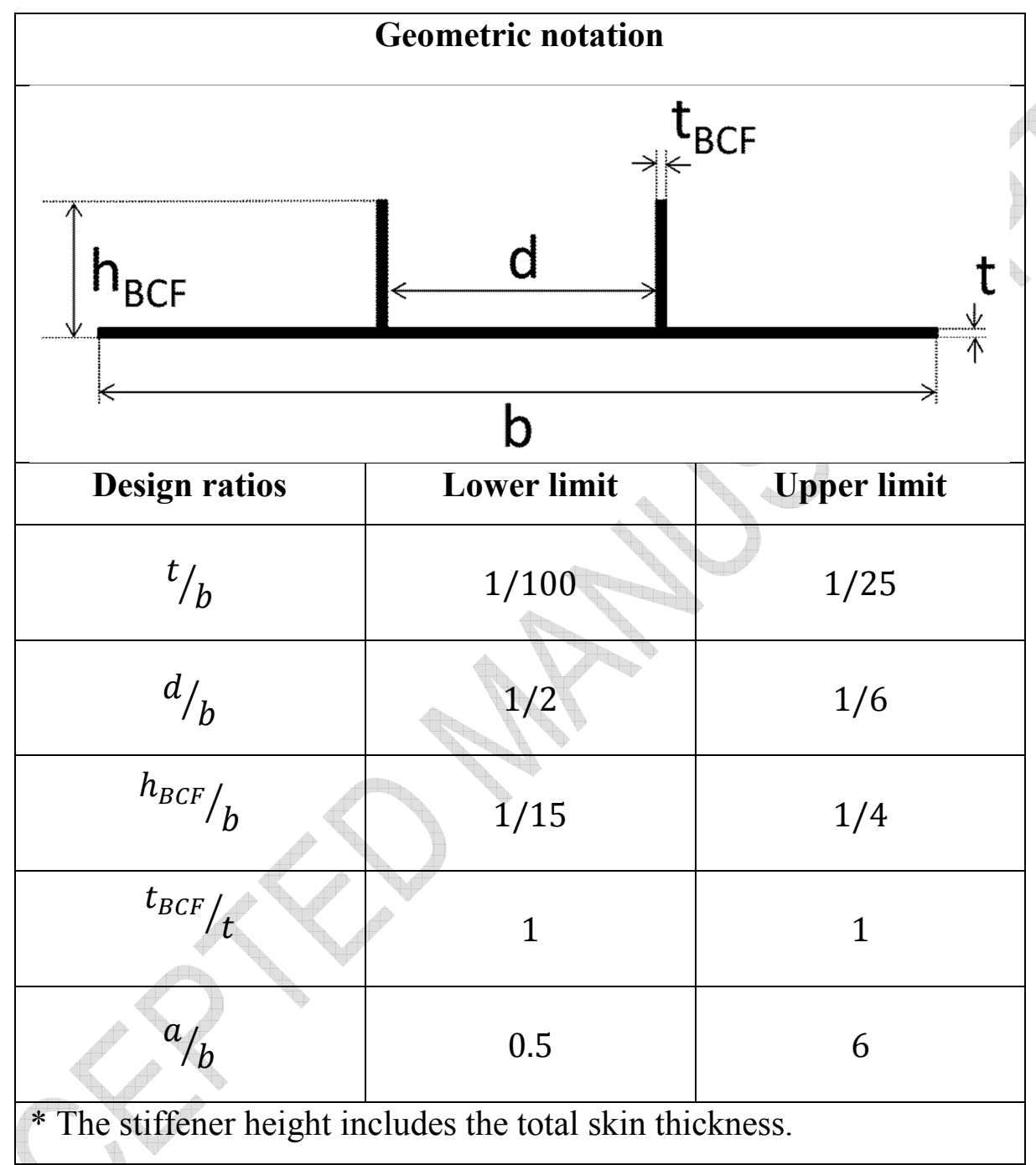


Table 2 -Design chart example use - problem specification.

\begin{tabular}{|c|c|}
\hline \multicolumn{2}{|c|}{ Problem Specification } \\
\hline Target Compressive Load Intensity (N/mm) & 1475 \\
\hline Material Yield Stress (N/mm $\left.{ }^{2}\right)$ & 590 \\
\hline Maximum Manufacturable Thickness (mm) & 18 \\
\hline Primary Stiffener Pitch (mm) & 100 \\
\hline Rib Pitch (mm) & 400 \\
\hline Young's Modulus, E (N/mm $\left.{ }^{2}\right)$ & 74918 \\
\hline Poisson's Ratio & 0.33 \\
\hline
\end{tabular}

Table 3 - Design chart example use - problem solution

\begin{tabular}{|c|c|c|c|c|}
\hline Number of BCF & $\mathbf{t} / \mathbf{b}$ & $\mathbf{h}_{\mathbf{B C F}} / \mathbf{b}$ & $\mathbf{t}_{\text {smeared }} / \mathbf{b}$ & Buckling Mode \\
\hline $\mathbf{1}$ & 0.023 & 0.180 & 0.026 & $\mathrm{~m}=1, \mathrm{n}=1$ \\
\hline $\mathbf{2}$ & 0.022 & 0.180 & 0.029 & $\mathrm{~m}=1, \mathrm{n}=1$ \\
\hline $\mathbf{3}$ & 0.021 & 0.180 & 0.031 & $\mathrm{~m}=1, \mathrm{n}=1$ \\
\hline $\mathbf{4}$ & 0.020 & 0.180 & 0.034 & $\mathrm{~m}=1, \mathrm{n}=1$ \\
\hline
\end{tabular}


Table 4 -Buckling and collapse load predictions along with experimental data.

\begin{tabular}{|c|c|c|c|c|c|c|}
\hline & & \multicolumn{2}{|c|}{ Experimental } & \multicolumn{2}{|c|}{ FE } & \multirow{2}{*}{$\begin{array}{r}\text { Theoretical } \\
(a / b=4.9)\end{array}$} \\
\hline & & $(a / b=4.9)$ & $\begin{array}{c}\text { Initial } \\
\text { buckling } \\
\text { mode }\end{array}$ & $(a / b=4.5)$ & $(a / b=5.0)$ & \\
\hline \multirow{2}{*}{$\begin{array}{c}\text { Specimen } \\
1\end{array}$} & $\begin{array}{c}\text { Initial } \\
\text { Buckling } \\
(\mathrm{kN})\end{array}$ & $\begin{array}{c}713.0 \\
\mathrm{~m}=2 \mathrm{~m}=1\end{array}$ & & $\begin{array}{c}571.6 \\
m=2 m=1 \\
(-19.8 \%)\end{array}$ & $\begin{array}{c}594.7 \\
m=2 \mathrm{~m}=1 \\
(-16.6 \%)\end{array}$ & $\begin{array}{c}584.1 \\
\mathrm{~m}=2 \mathrm{~m}=1 \\
(-18.1 \%)\end{array}$ \\
\hline & $\begin{array}{c}\text { Ultimate } \\
\text { Collapse } \\
(\mathrm{kN})\end{array}$ & $\begin{array}{c}764.2 \\
m=2 \mathrm{~m}=1\end{array}$ & & $\begin{array}{c}723.9 \\
m=2 m=1 \\
(-5.3 \%)\end{array}$ & $\begin{array}{c}727.9 \\
m=2 \mathrm{~m}=1 \\
(-4.8 \%)\end{array}$ & $\begin{array}{c}726.2 \\
\mathrm{~m}=2 \mathrm{~m}=1 \\
(-5.0 \%)\end{array}$ \\
\hline \multirow{2}{*}{$\begin{array}{c}\text { Specimen } \\
2\end{array}$} & $\begin{array}{c}\text { Initial } \\
\text { Buckling } \\
(\mathrm{kN})\end{array}$ & $\begin{array}{c}728.0 \\
\mathrm{~m}=2 \mathrm{~m}=1\end{array}$ & & $\begin{array}{c}609.2 \\
m=2 n=1 \\
(-16.3 \%)\end{array}$ & $\begin{array}{c}616.1 \\
m=2 m=1 \\
(-15.4 \%)\end{array}$ & $\begin{array}{c}608.3 \\
m=2 \mathrm{~m}=1 \\
(-16.4 \%)\end{array}$ \\
\hline & $\begin{array}{c}\text { Ultimate } \\
\text { Collapse } \\
(\mathrm{kN})\end{array}$ & $\begin{array}{c}758.4 \\
m=2 \mathrm{~m}=1\end{array}$ & & $\begin{array}{c}706.5 \\
m=2 n=1 \\
(-6.8 \%)\end{array}$ & $\begin{array}{c}717.2 \\
m=2 \mathrm{~m}=1 \\
(-5.4 \%)\end{array}$ & $\begin{array}{c}706.35 \\
\mathrm{~m}=2 \mathrm{~m}=1 \\
(-6.9 \%)\end{array}$ \\
\hline
\end{tabular}


Figures:

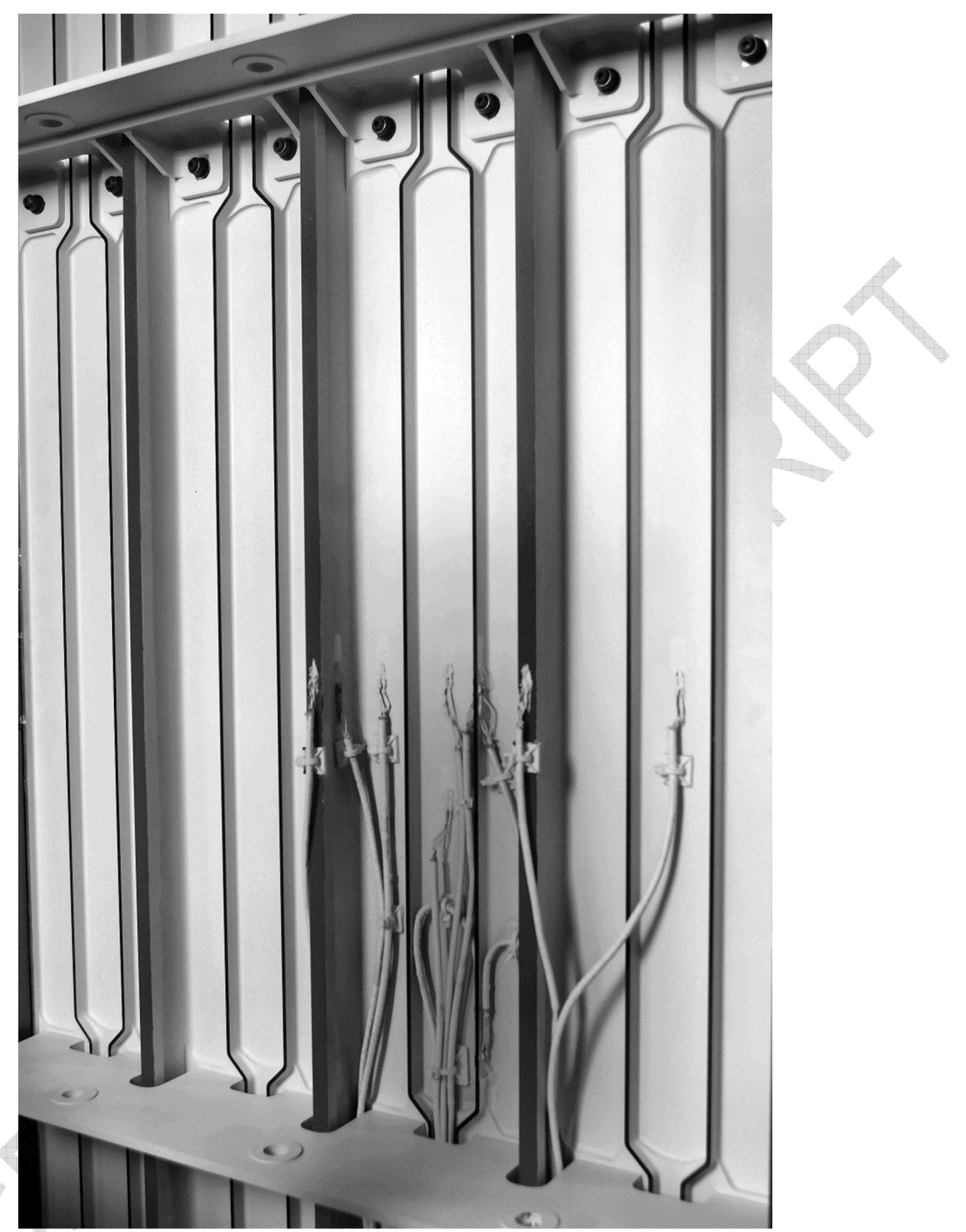

Figure 1 - Example of panel structure with BCF. 


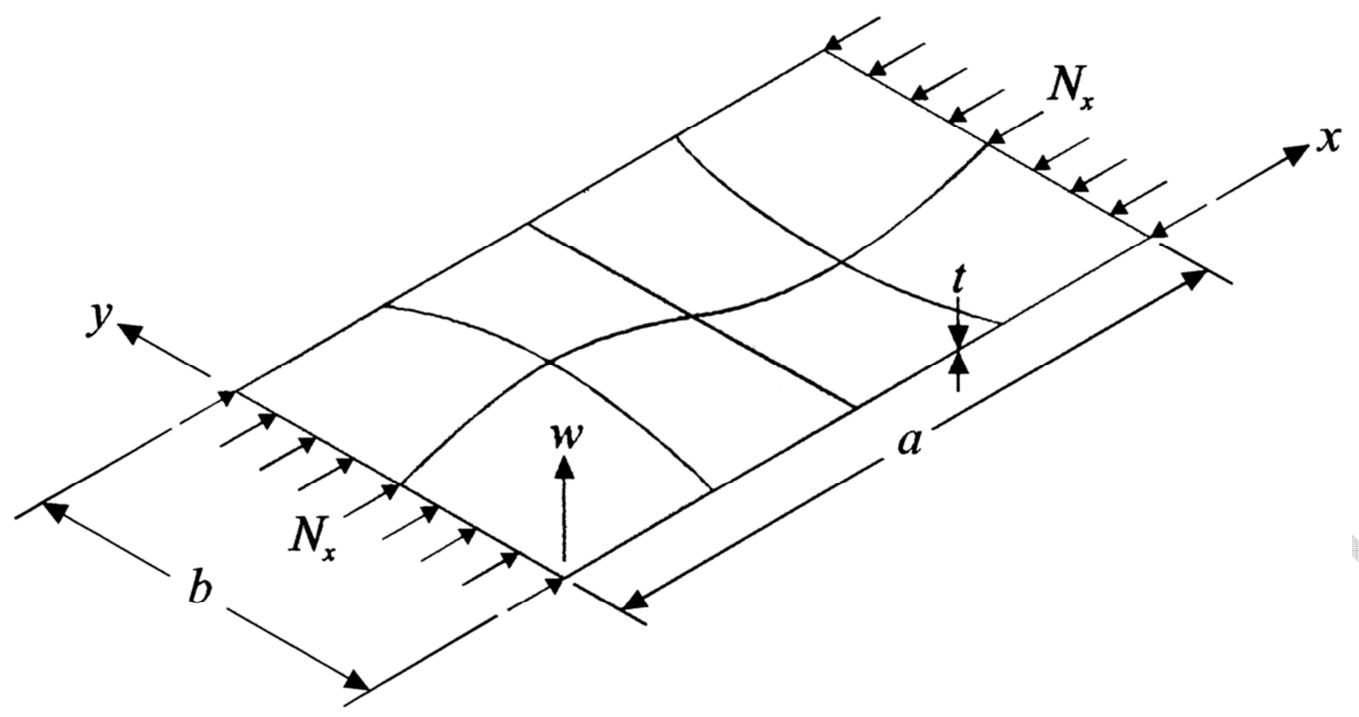

Figure 2 - Buckling mode of a simply-supported rectangular plate. 


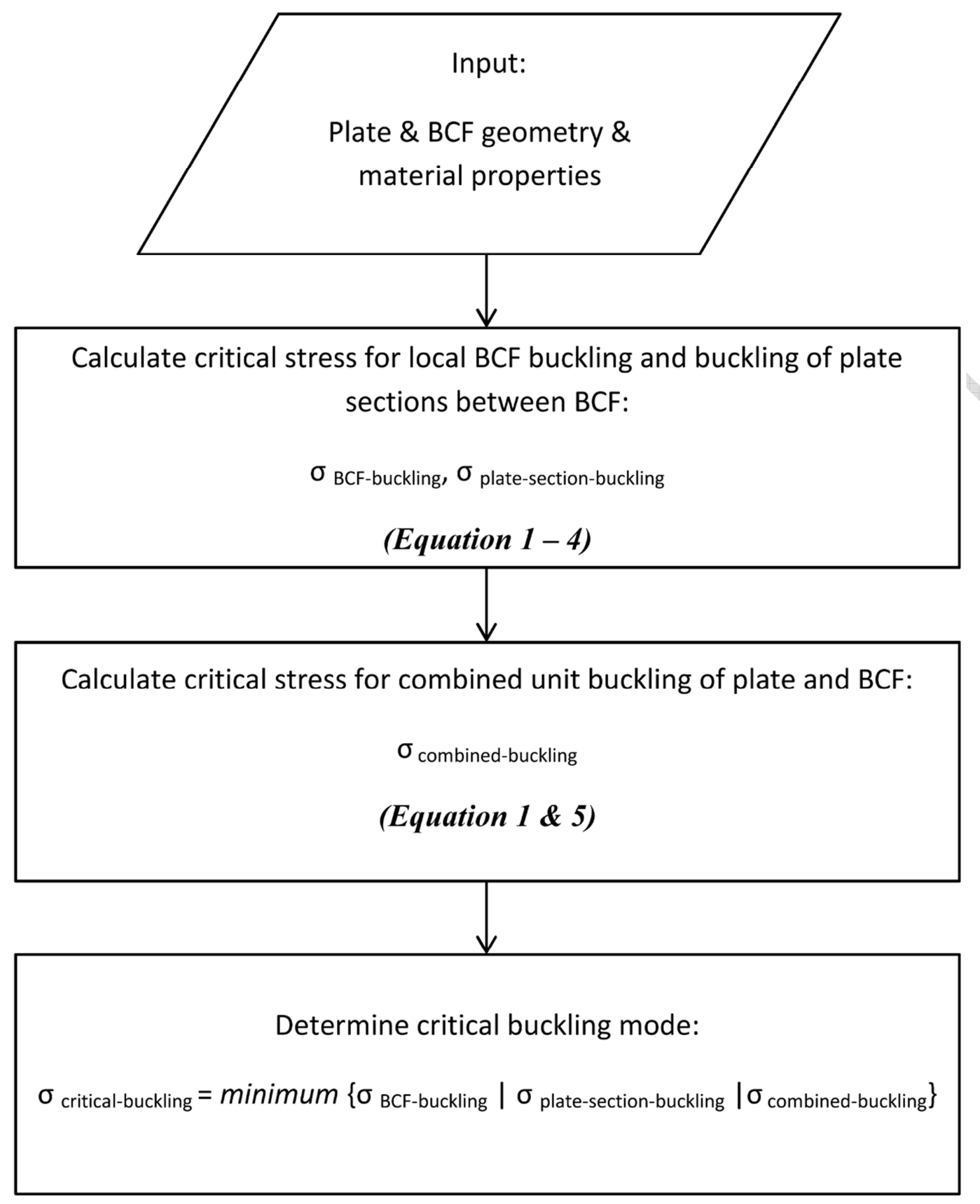

Figure 3 - CPT based analysis flowchart. 
a)

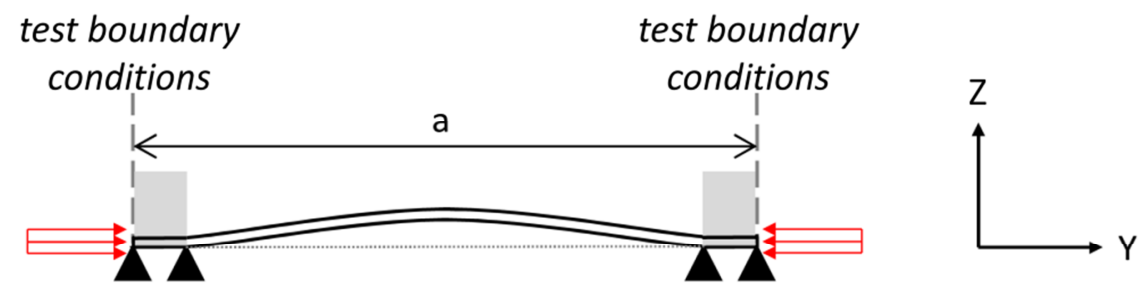

b)

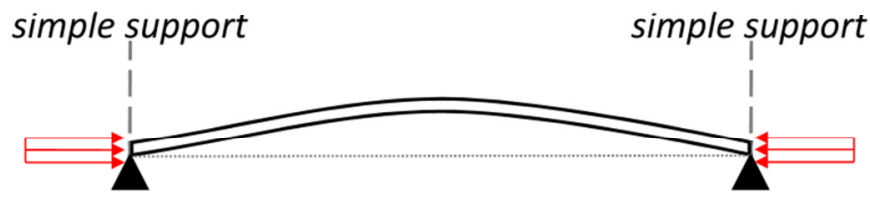

c)

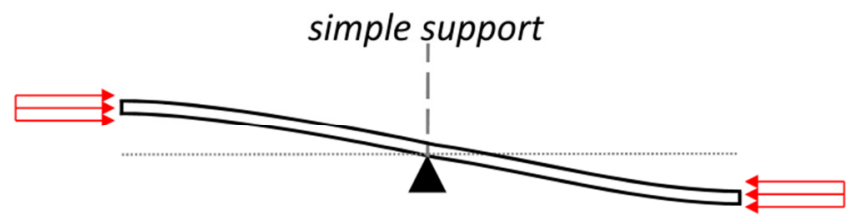

d)

simple support

simple support

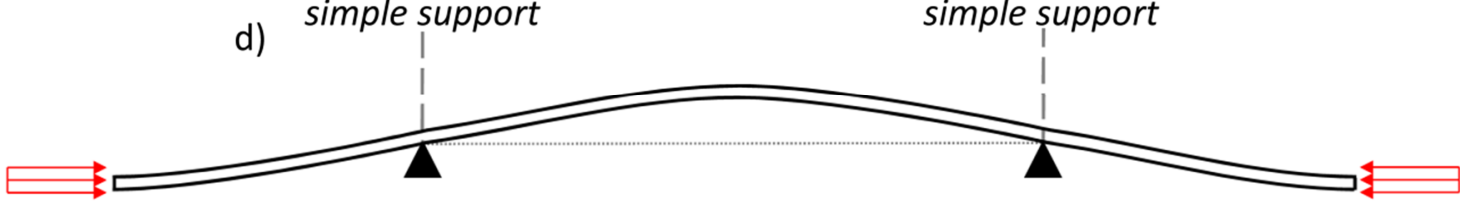

Figure 4 - Boundary conditions on skin bay loaded edges. 


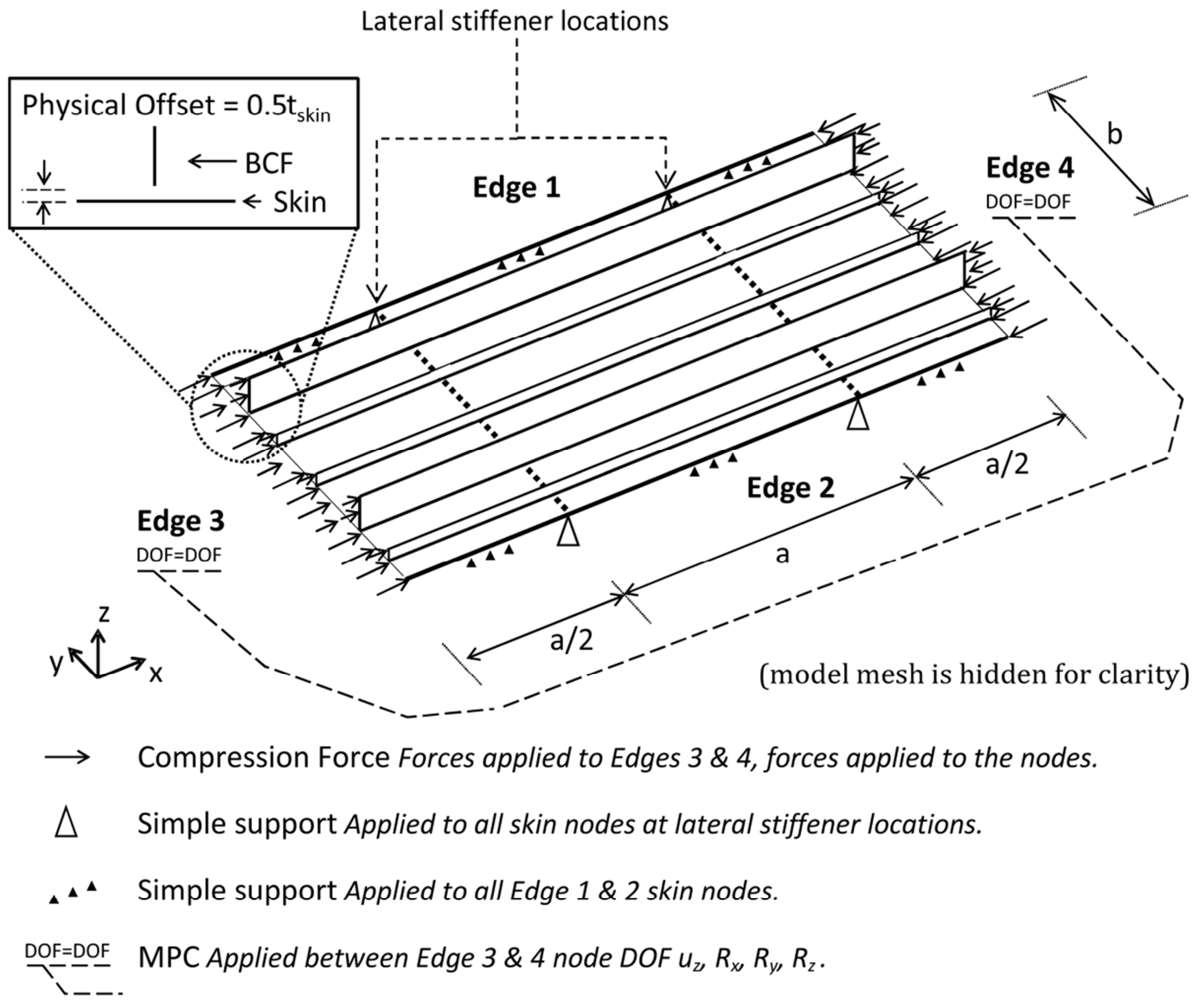

Figure 5 - FE model loading and boundary conditions. 

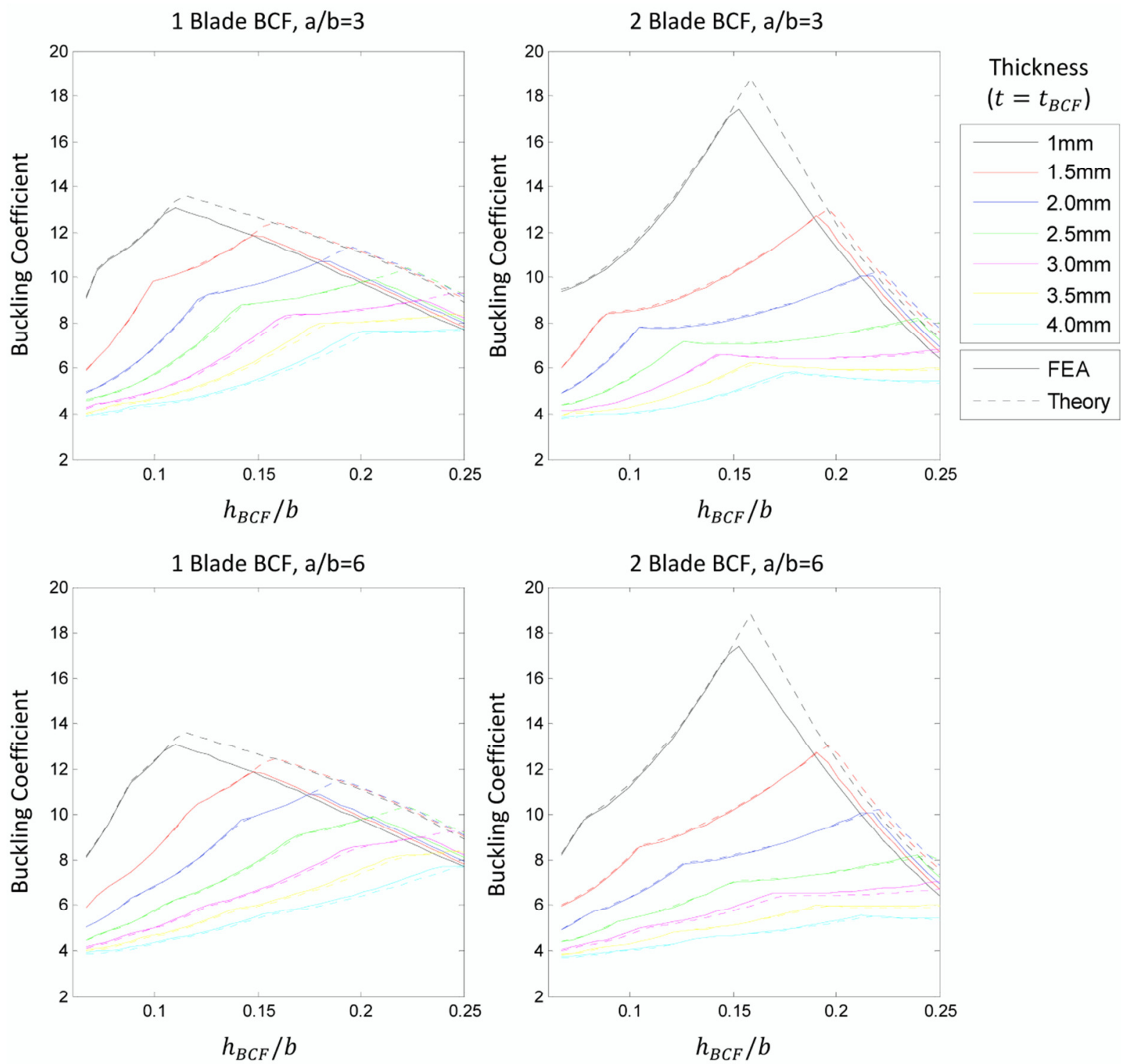

Figure 6 - Typical comparison of classical analysis and FE method predictions. Solid lines refer to theoretically calculated buckling coefficient, and dashed lines refer to FE predicted buckling coefficients. 

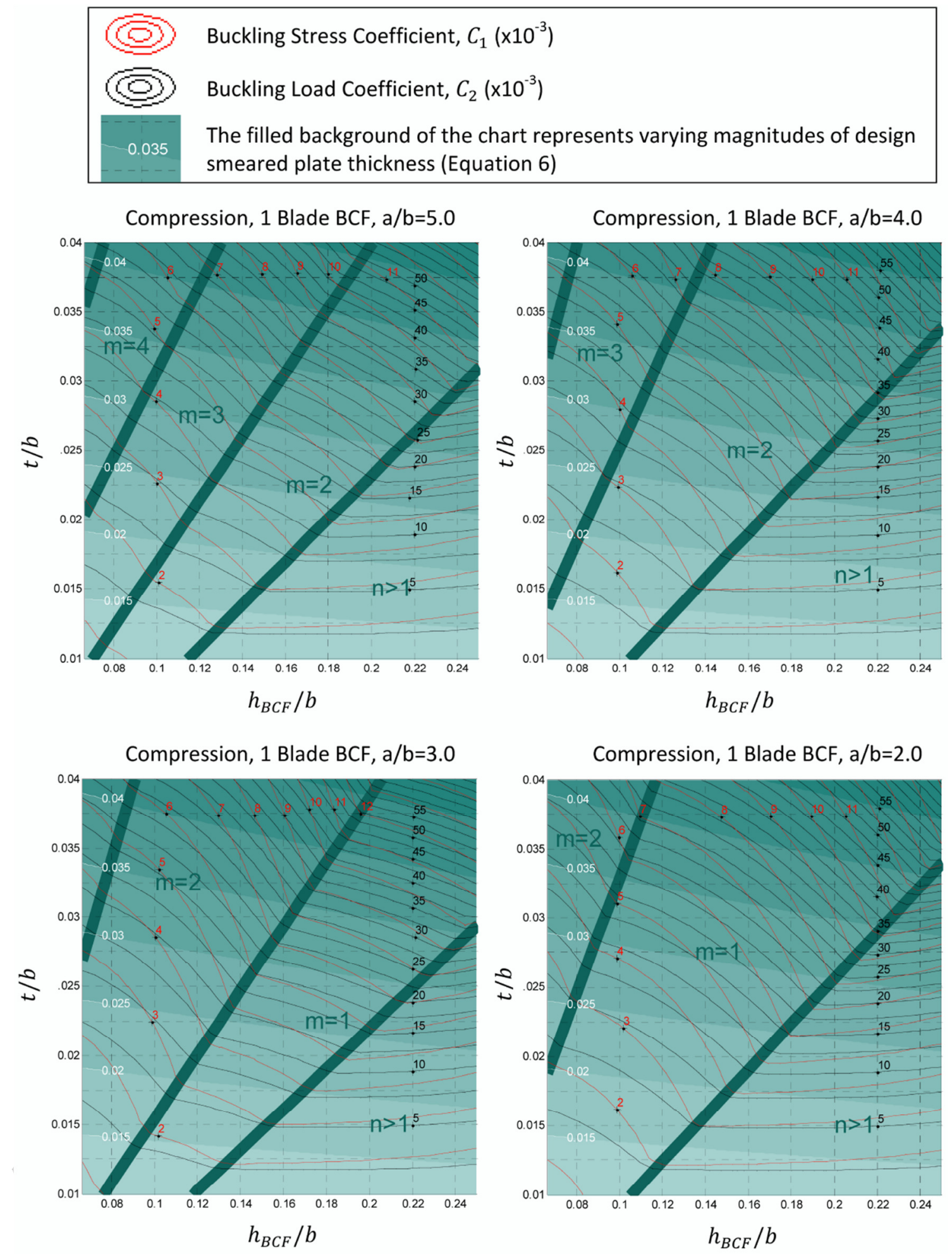

Figure 7 - Design Chart data for varying aspect ratio (for single centrally located prismatic $\mathrm{BCF}$ and $\left.t=t_{B C F}\right)$. 

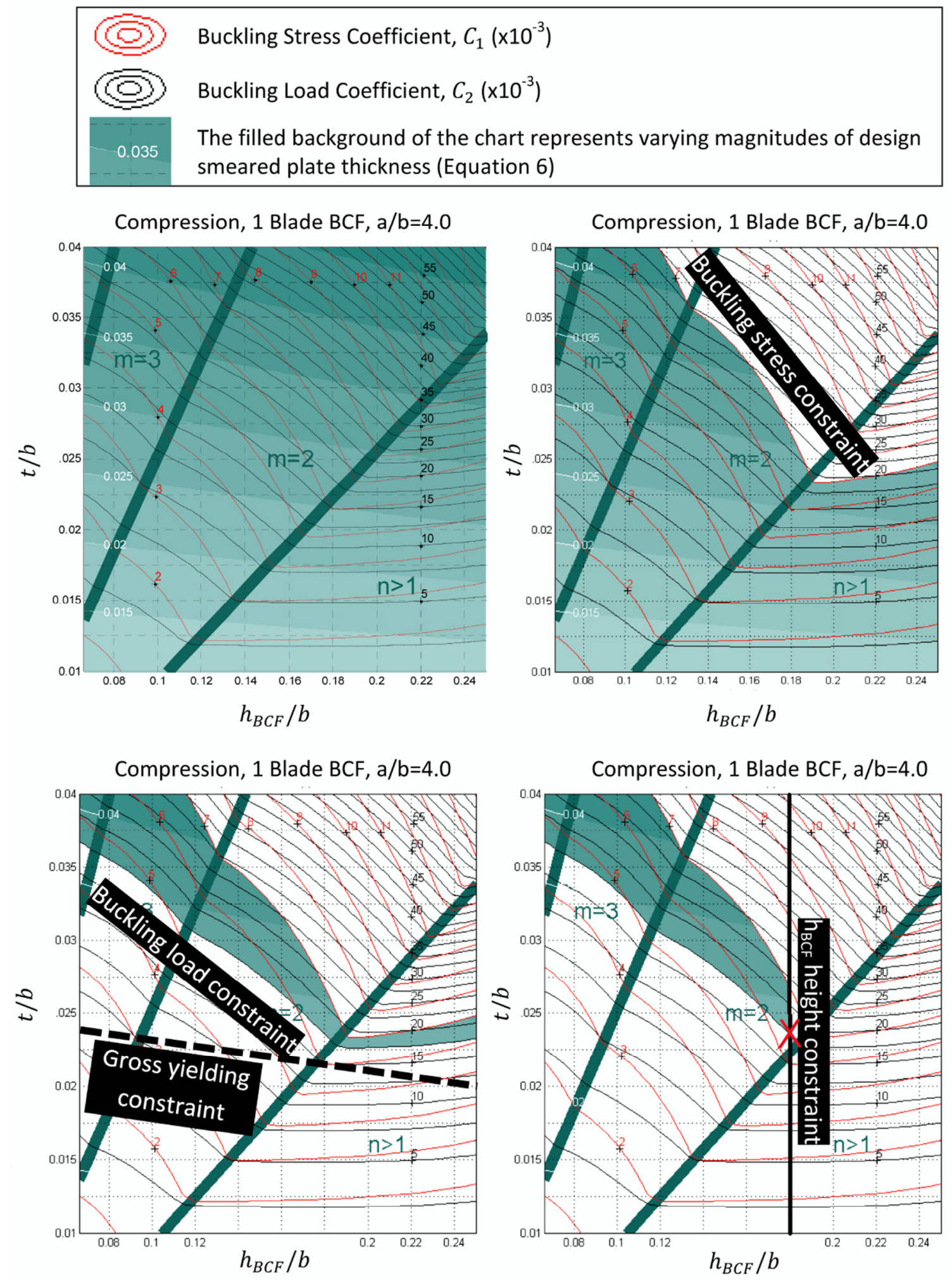

Figure 8 - Illustration of design chart use. 


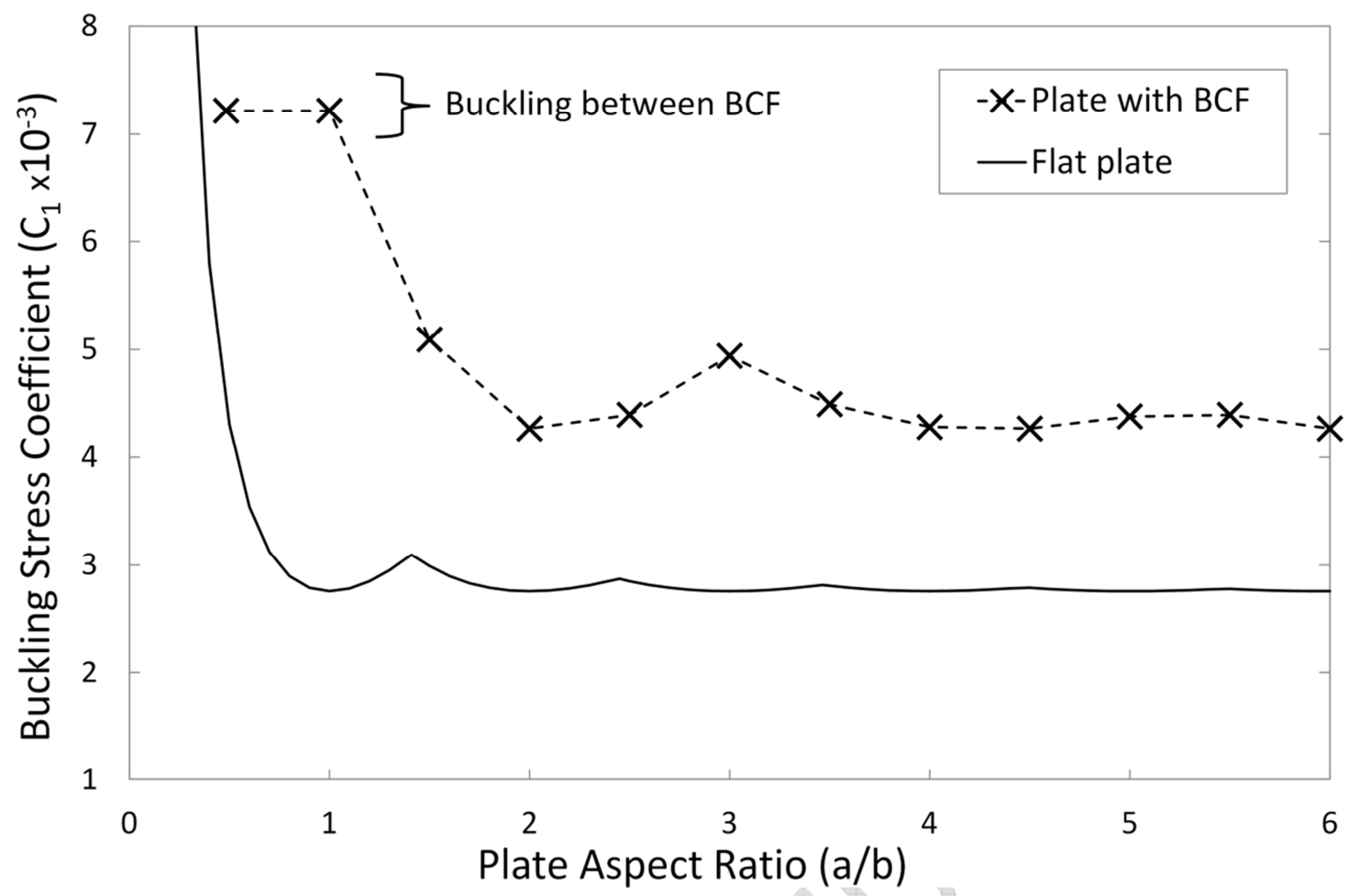

Figure 9 - Variation of stress buckling coefficient with aspect ratio for a flat plate and a plate with a single $\mathrm{BCF}\left(\mathrm{h}_{\mathrm{BCF}} / \mathrm{b}=0.158, \mathrm{t} / \mathrm{b}=0.025\right)$. 

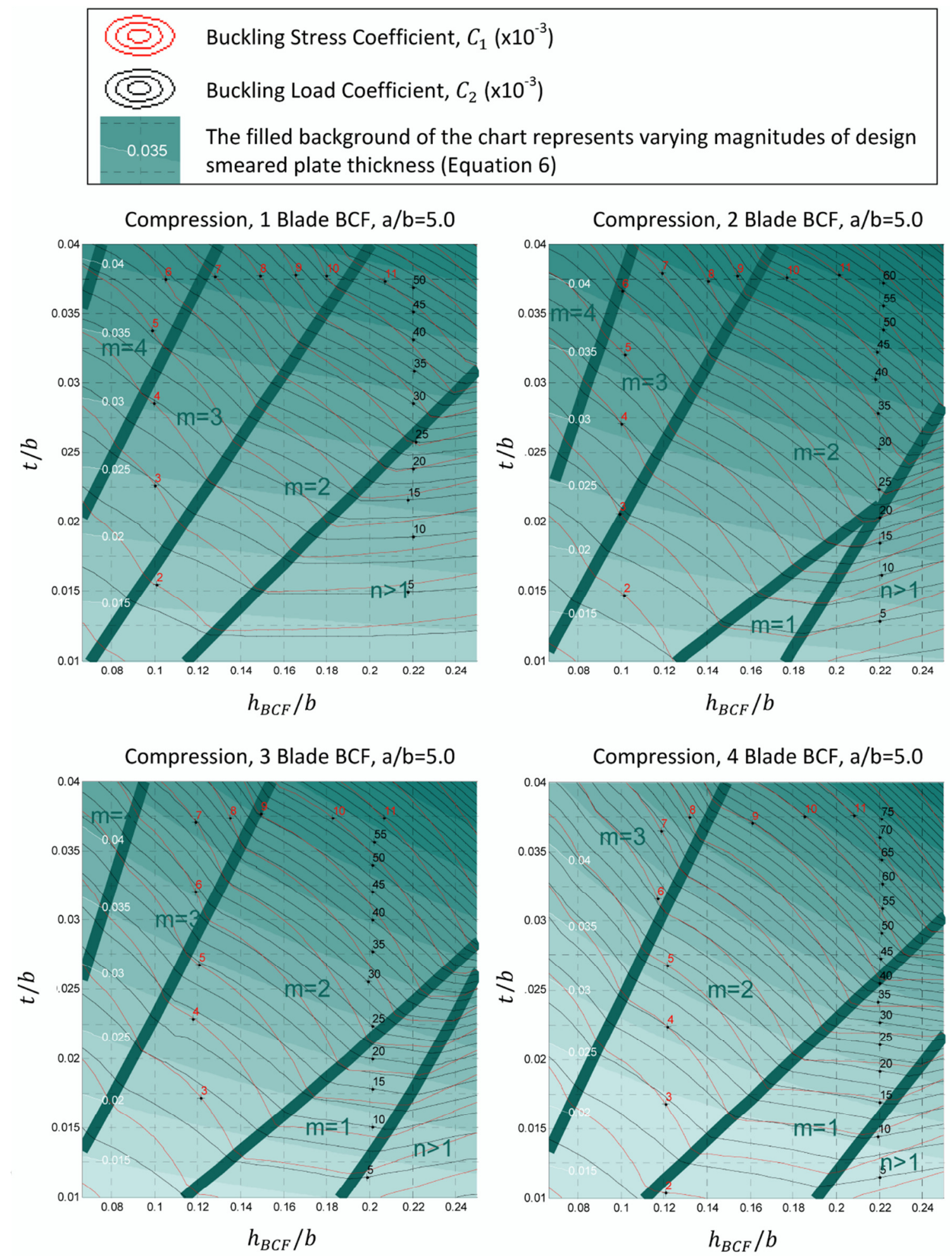

Figure 10 - Design Chart data for varying numbers of prismatic BCF (1 to 4). 

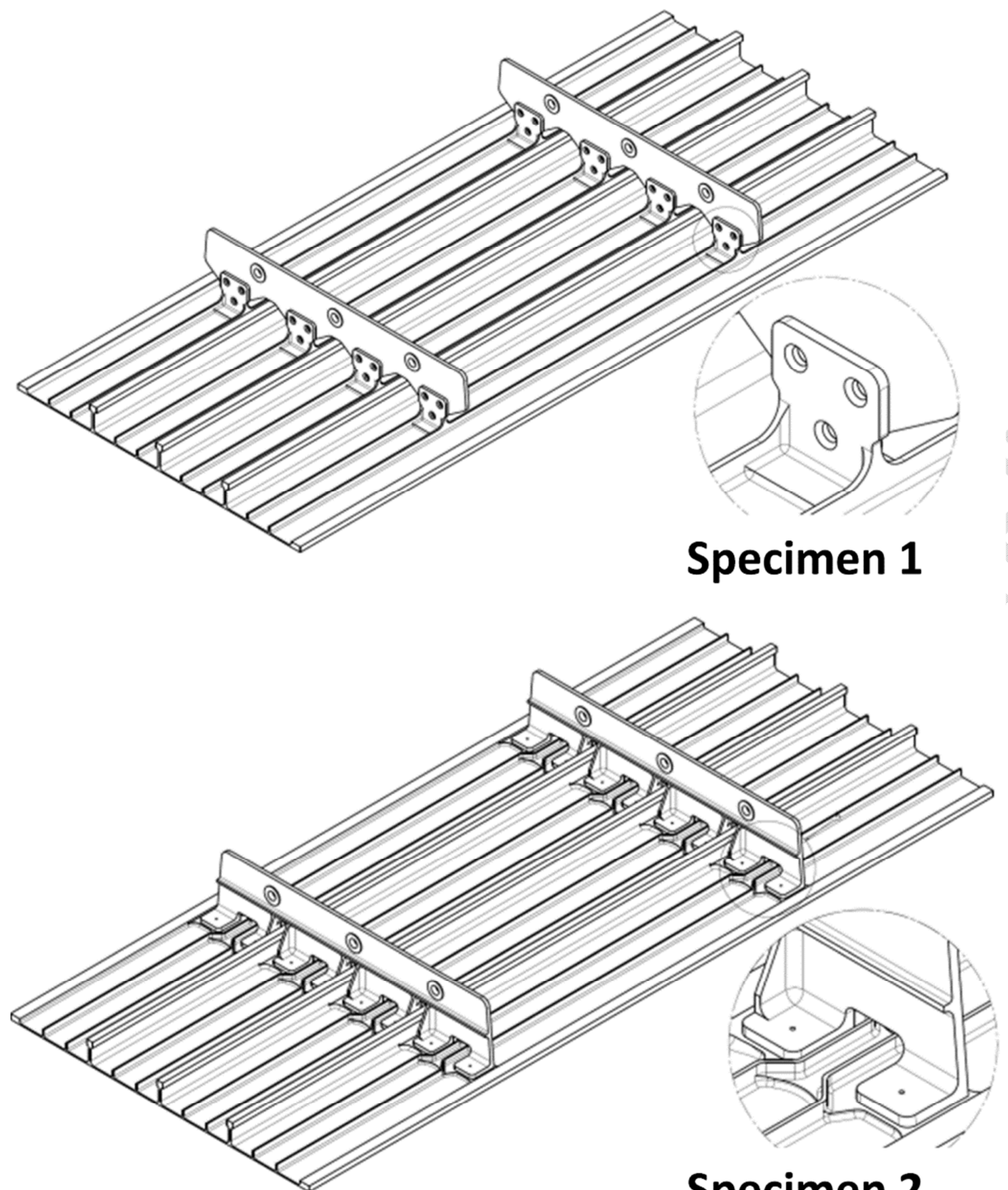

Specimen 2

Figure 11 - Experimental test specimens incorporating Buckling Containment Features. 


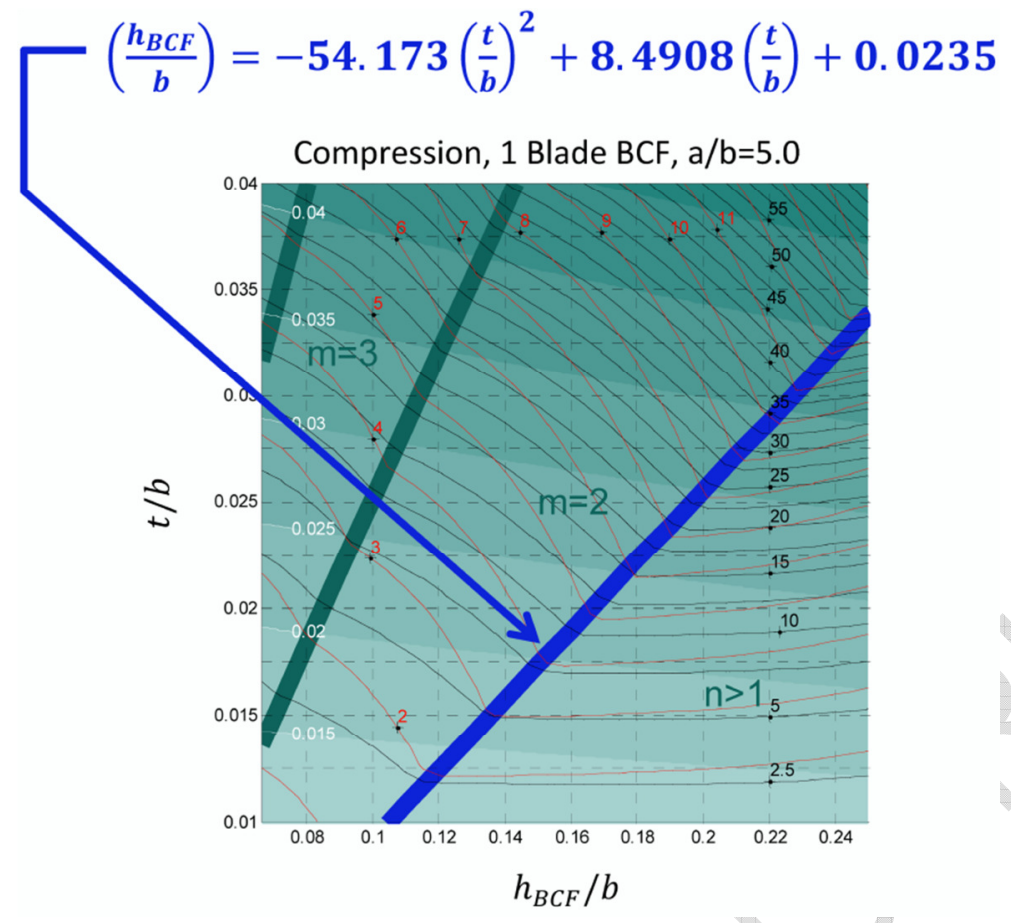

Figure 12 - Design Chart (Compression, $1 \mathrm{BCF}$, $\mathrm{a} / \mathrm{b}=4.0$ ), showing the location of optimum designs as a blue coloured line. 